\title{
Adolescents and the 'Instagramability' of Places - An Explorative Study on Spatial Practices in Social Media
}

\author{
Christina Reithmeier and Detlef Kanwischer \\ Goethe University Frankfurt/Main, Germany
}

\begin{abstract}
Social media are everyday companions for adolescents, enabling them to communicate and share their experience of the world. With the rise of social media, location has gained importance as an organizing principle of online content. In addition, actions like taking, geotagging and uploading pictures on the go mediate space in a new way. In this article, we explore the production of space through social media, and the emerging receptive processes among young people against the background of a changed allocation of spatial meaning through digitization processes. The ubiquity of software leads to a production of 'coded spaces' and 'code/spaces'. We give an overview of contemporary research within geography that examines the production of space in social media and identify possible ways of thinking about space in social media. In order to analyse young people's spatial practices in social media, we conducted interviews with adolescents regarding their social media habits. Our first analysis reveals several spatial practices that occur on Instagram: youngsters select locations specifically for Instagram, geotag places that they deem exceptional, and edit their photos with filters. Our analysis confirms that software leads to the emergence of new spatial practices. The production and reception of space in the context of digitization raise a series of questions regarding the theoretical conception of space on social media.
\end{abstract}

\section{Keywords:}

social media, spatial practices, adolescents, instragram, digital geographies

\section{Introduction}

Social media are 'places' where people engage with a variety of topics, articulate opinions, share feelings, and communicate in different forms. Every video, hashtag or post has the potential to go viral. There are countless examples of posts on social media that went viral and entered traditional media, e.g. Greta Thunberg sitting on the floor in an overcrowded German train, sparking a debate about data privacy (Frankfurter Rundschau, 2019), or Donald Trump's infamous tweets leading to further tensions between the USA and Iran (Frankfurter Rundschau, 2020). As Stalder (2018) argued, we are experiencing a cultural transformation in which computer networks are the key infrastructure for all aspects of life - leading to a digital 
condition. We produce space online and offline everyday through our actions and communication, blurring boundaries between 'online' and 'offline'. Under these conditions, as Leszczynski (2015) puts it, location has become an organizing principle for online content, information services and everyday life - especially on social media.

There are various social media platforms, designed for different purposes and used by different groups. While Facebook and Twitter focus on news distribution, Instagram, Pinterest and Snapchat are used mainly to exchange photos or videos (Highfield \& Leaver, 2016). With the proliferation of mobile phones and smartphones, virtually anybody is able to take a quick snapshot and post it online, leading to an increased integration of visual content (Highfield \& Leaver, 2016). Not only do photos of food, pets or selfies proliferate online, but places have also gained more and more attention and now play a big role on social media. The European Central Bank Headquarters in Frankfurt, for example, was tagged on 39,918 images on Instagram's explore feature (see Figure 1). It is noticeable not only that the building was photographed from a certain angle, but also that a filter was used to dramatically intensify the colours.

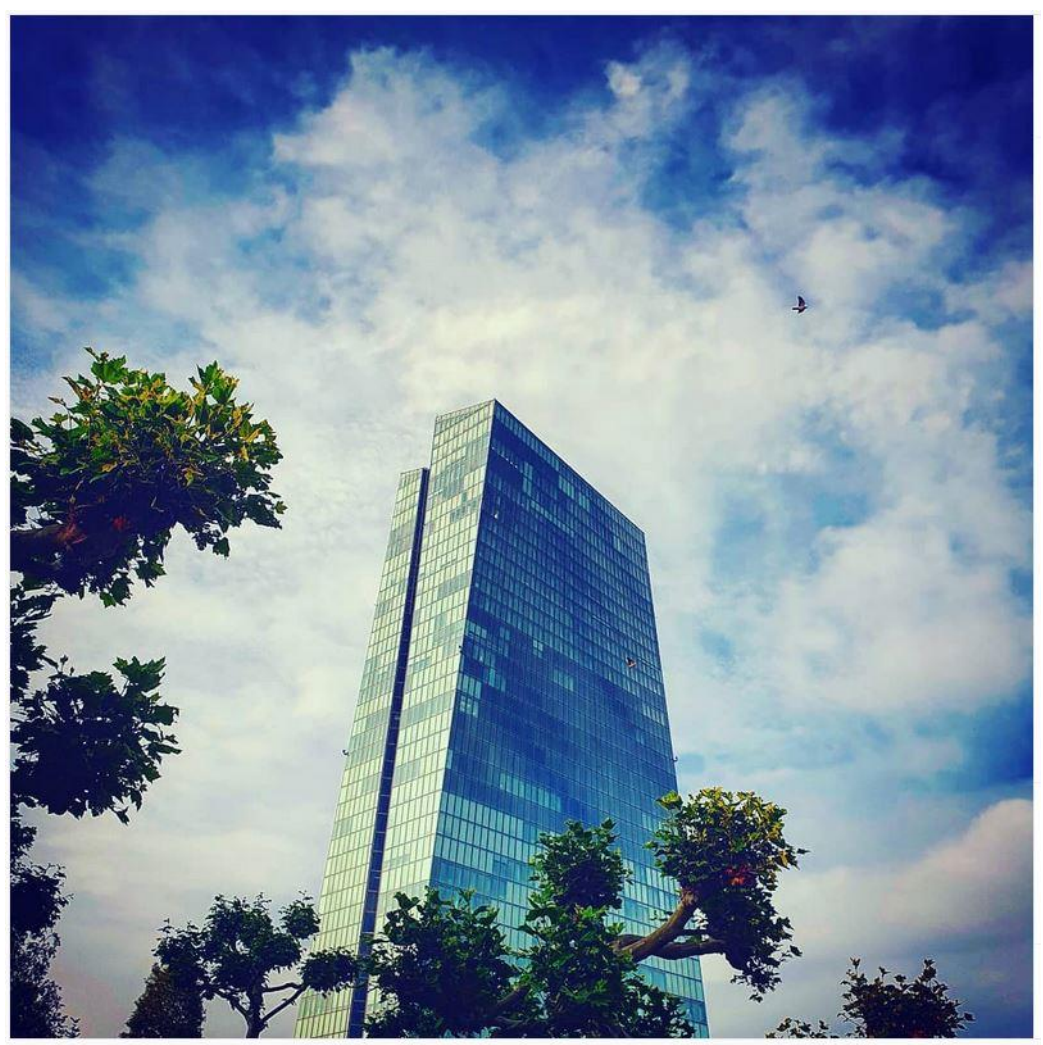

Figure 1: European Central Bank headquarters in Frankfurt 2019 (Source: https://www.instagram.com/p/-BzlOILlotKY/) 
The photo shows only a fragment of the headquarters and renders the surroundings invisible. On social media - particularly on platforms like Instagram - it is common practice to edit photos. Users produce images of places that are represented in a new aesthetic form. Social media enable users to communicate an experience of space and place online with others, to render invisible spaces visible, to offer image details, and to alter the meaning of places. The European Central Bank Headquarters are located next to the 'Hafenpark', a park on the banks of the Main River which also features a skate park. It is a popular location among young people and a prominent place on Instagram. Social media are everyday companions for adolescents, and the production and consumption of unmoderated constructions of space have an impact on their self-perception and their relation to the world. Although practices and features may vary between platforms, they morph and reappear on other social media platforms (Highfield \& Leaver, 2016); 'Stories', for example, originated on Snapchat, but were such a popular feature that they were implemented on Instagram, WhatsApp and the YouTube mobile app.

Adolescents take part in producing space on social media, yet little is known about their spatial practices on Instagram and why they exercise them. To develop a better understanding of how space is reconfigured through social media, and which practices and processes of reception emerge among young people against the background of the changed spatial allocation of meaning through digitization, we take a closer look at contemporary geographic research and analyse interviews with adolescents on their use of social media platforms.

We start with an introduction of our theoretical framework of digital space and outline studies that were concerned with the production of space in social media. We then present our case study: a brief explorative analysis of interviews with adolescents who actively use Instagram in their everyday life. Finally, we discuss our findings regarding the production of space and the process of reception under digital conditions.

\section{Digital space, and places on social media}

Technological innovations have led to the spread of telecommunications, the internet, and profound digitization of everyday life. This transition results in a digital turn within geography, as Ash et al. (2018: 29) have stated, where 'the digital is mediating and augmenting the production of space and transforming socio-spatial relations'. Space is increasingly augmented by virtual interactions, so that life is determined by an interplay of online and offline contexts. Content is created in an interaction between people and non-human actors in which 'code' plays a major role (Kitchin \& Dodge, 2011). Code consists of instructions and rules, producing programs that operate hardware and take multiple forms. Kitchin and Dodge (2011) distinguish between 'coded objects', which are non-networked objects that use code to function or store digital data that is only accessible via software, and 'coded infrastructures', which consist of networks that link coded objects that are monitored and regulated partially or fully by code. Moreover, they define 'coded processes' as the transaction and flow of digital data across coded infrastructure. Finally, 'coded assemblages' occur where several coded infrastructures coincide and work together. Code is embedded in everyday life, producing these coded objects, infrastructures, processes and assemblages. Software enables everyday actions as well as the creation of new spatial formations, which Kitchin and Dodge (2011:261) refer 
to as 'code/space': 'A space that is dependent on software for it to be transduced as intended. Here the relationship between software and space is dyadic; they are mutually constituted, that is produced through one another.' Smartphones, mobile internet and social media allow users to share their location, to rate locations on Google, to take photos and send them directly via a messenger, or to upload them onto social media platforms whenever they wish. Therefore, the 'digital' is reshaping the production and perception of space, place, landscape and environment (Ash et al., 2018).

Social media platforms are coded infrastructures that play a vital role in our everyday life and serve a variety of purposes, e.g. sharing images (Instagram) or microblogging (Twitter). Information distribution via these platforms is becoming increasingly interactive. They mediate reality as the product of an interplay of technologies, society and spatial relations, helping us to make sense of the world. With the rise of coded infrastructures, location has become an organizing principle for online content and information services. Instagram's interface structures the content via spatial activities and therefore affects the user's experience (Leszczynski, 2015). Visuality also plays a major role in social media as the main medium for creating and presenting an online identity. Visual content is used to present news or comments; it is placed next to political, legal, economic, technological and sociocultural debates (Highfield \& Leaver, 2016).

Ingrained in everyday life and a venue where cultural and social changes take place, the internet has become an object of research. A new medium requires new methods to fully understand it in its context (Rogers, 2013). Therefore, a variety of new research methods based on a variety of theoretical concepts and tools have emerged over the last decade. So far, some nongeographic research on Twitter (e.g. Bruns \& Burgess, 2011; Bruns \& Stieglitz, 2014), Instagram and Facebook (e.g. Burgess et al., 2017; Highfield \& Leaver, 2016) has been carried out, but there has been less research in the field of geography that focuses on the production of space in social media.

Shelton et al. (2015) conducted a study analysing Twitter data to examine how big data sources can be mobilized for understanding urban socio-spatial processes. Segregation and inequalities were initially confirmed by pure mapping, but Shelton et al.'s data, through additional analysis using methods drawn from critical GIS, revealed them to be less clear and more complex, and to present. Butler et al. (2018) have a similar research interest as Shelton et al (2015). Their study aimed to investigate the stigmatization of places on Twitter. The data revealed that male users tend to refer to other places and paint a stigmatizing image from a distance, while female users often write about their home areas. This study raises the question of who determines the social media discourse on certain spatial images.

Kelley (2013) studied Foursquare in relation to the meaning of geosocial data in the context of socio-spatial 'imaginations' and the production of space on social media. His data revealed that observing the city through Foursquare constructs a patchwork landscape with invisible and visible spots.

Another study on Foursquare, carried out by Fekete (2015), asked how social media render certain ethnic groups invisible. She postulated that the geoweb is racially divided and does not eradicate social inequalities. Her data revealed that Foursquare appeals mostly to a white population, leading to an over-representation of white businesses and venues, while 
simultaneously under-representing venues in African-American neighbourhoods. She concluded that this lack of representation has a real-world implication, namely that people using the 'explore' feature will see predominantly venues in white areas, leaving others invisible and therefore inscribing digital inequalities.

Lundgren and Johansson (2017) took another approach to the production of space in social media, analysing how rural space is presented on Facebook. Their analysis revealed that rural space is portrayed as dying while at the same time also being very much alive, and that online activities like debates often coincided with offline activities like protests. They proposed that social media enable people to voice their opinions, and in doing so they contribute to the production of space and certain places. Boy and Uitermark (2017) traced the relationship between social media and peoples' presentation of their city on Instagram. Their data revealed that the users' feeds presented a limited number of places in a curated way and that the visual representation aestheticized their everyday life, which therefore never appears ordinary. This results in places being rendered either more visible or invisible, inequalities are re-inscribed, and the image of the city becomes fragmented.

Although these studies deal with different platforms and answer different questions, there seem to be common notions of digital space that the platforms' users produce: space is curated. Individuals preserve well-chosen moments and train themselves to spot moments that are worthy of preservation (Boy \& Uitermark, 2017; Lundgren \& Johansson, 2017). Social media enable a transformation of aesthetics: places are shown from certain angles or through filters provided by the platforms or other applications (Boy \& Uitermark, 2017; Kelley, 2013). Why do users choose certain places, present them in a certain way, and how do these representations impact the places as well as the users? Social media not only permit the widespread dissemination of different perceptions of places, but also facilitate the production and dissemination of new meanings (Butler et al., 2018; Kelley, 2013; Lundgren \& Johansson, 2017). Furthermore, social media platforms confirm status and (in-)visibility of places (Boy \& Uitermark, 2017; Butler et al., 2018; Fekete, 2015; Shelton et al. 2015). Spatial practices lead to hotspots of activity and alleged inactivity. But who is talking about the location or evaluating it, who is visiting these places due to their online representation, and what kind of socio-spatial inequalities may occur as a result.

The production of space in social media take various forms, under various conditions. Since social media appeal foremost to young people, the question of how they experience places has become a crucial one, which we address in our case study.

\section{Case study: Adolescents and Instagram}

To understand how place is produced in social media by adolescents, in 2020 we conducted in-depth narrative interviews with 10 young people (5 females and 5 males), aged 14 to 18 . All live in Frankfurt, own a smartphone, and use various social media platforms on a daily basis. We approached them in a youth centre and at a sports club. The interviews were held in German (quotations have been translated into English). We have changed their names and anonymized any sensitive data to protect their identities. Against the background of the 
changed spatial allocation of meaning through digitization processes, we use our textual corpus to gain a first impression of the spatial perception and practices emerging among young people.

We use a grounded theory approach for our analysis because of its open, explorative character. Grounded theory enables the development of new theoretical approaches based on peoples' everyday experiences. The aim of our analysis is to formulate new theoretical approaches regarding the production of space in social media. Grounded theory consists of the following steps: open coding, axial coding and selective coding. First, ideas are identified via text samples (theoretical sampling) and codes are formed. In the second step, the codes are transferred into categories. In the third step, core categories are formed (Breuer 2010).

Our interviews were divided into different sections: biographical background, use of social media platforms, digital practices, construction and perception of space, and visibility of algorithms. We asked a range of questions covering the participants' backgrounds, favourite social media platforms and content, and posting habits on different social media platforms. For this short explorative study, we decided to focus on Instagram because it was the most widely used platform and all participants had access to it. As already mentioned, Instagram is a visual platform that structures its content via spatial activities and allows users to search for places using geotags or hashtags. This led us to the assumption that users experience and post location-based content. First, we traced the young people's consumption and active production of posts on Instagram. Through open coding, we identified possible categories regarding their spatial practices: choosing locations, geotagging locations, editing locations, navigating through locations, and perception of locations. In the sections which follow, we present and discuss these categories regarding spatial practices, and our preliminary results.

\section{Results}

All the adolescents except one use Instagram on a daily basis. Their day usually starts with passive consumption as they browse different social media platforms and view new messages on WhatsApp or Instagram feeds. Although they exhibit multiple overlapping habits and practices, there are also differences regarding their use and uploading behaviour that lead to the production and perception of places on Instagram.

\subsection{Choosing locations}

Young people often think about the suitability of a location before taking a picture, although they also take quick snapshots of situations and places. They consider their home to be too ordinary a place for Instagram. Hence they hardly ever post their domestic activities. Isabella has strong opinions regarding how 'instagramable' places and situations are; she would never take a picture with a background that she perceives as unattractive, like an untidy room. She is very aware that her pictures only show a small segment or snippet, but she posts them regardless. In her opinion, the only purpose of taking a picture is to upload it to Instagram and share it with her followers: 'otherwise the picture doesn't do anything for me'. 


\subsection{Geotagging locations}

When uploading pictures of their homes, the youngsters do not geotag them not just because they are concerned about their privacy. Sarah says: 'When I'm in Frankfurt, I won't tag it in the picture. I have one picture where I am at home, but I didn't tag it.' Isabella elaborates similarly: 'I want to tag places that seem cool, but not my home.' Sarah tends to tag places she finds exotic and wants to share with her followers. Geotags also help to conserve memories, serve as evidence of adventures and, as Jan puts it, tell a story. Our participants like to post emojis alongside textual descriptions of their pictures.

\subsection{Editing locations}

The aesthetics of their uploaded images seem to play a big role: Melanie, Isabella, Sarah and Jan all edit their photos using different filters, or by heightening contrast or adjusting saturation. Only Finn does not use any filters because he thinks it establishes a world of illusion that only exists on social media and covers up reality. Melanie strives for her Instagram feed to appear harmonious and uniform. Sarah goes as far as wanting to remove all her pictures, re-sort them, and edit them with a uniform filter before re-uploading.

\subsection{Navigating through locations}

Besides using Instagram as a photo-sharing and uploading platform, youngsters use it for navigation purposes. They use Instagram's 'explore' feature to browse places they have never been to but plan on visiting. Melanie and Jan like this feature because they can get first impressions of a place, as well as receive suggestions of locations to visit like restaurants or sightseeing spots. The feature also enables them to compare official representations of restaurants, cafés or holiday destinations to their own presentations of them on Instagram.

\subsection{Perception of locations}

The representation of places on Instagram does not entice Sarah to visit these places - only friends or family do that. Nor does she look for places she is already familiar with: 'I would not look for a place like Hafenpark on a whim, because I know that place pretty well and I would not take the representation seriously. I can determine my own personal perception [of a place].' Isabella consumes shared images of places, which she then proceeds to visit if she has the chance of doing so. Finn prefers to walk through a city or landscape and discover and explore places on the way, because he does not want social media to tell him 'what looks good and interesting, and what does not'. Melanie feels that 'meme-pages' that present places in a certain way often contribute to a negative image of those places and sometimes lead to avoiding the locations. The youngsters often referred to the 'Bahnhofsviertel', near Frankfurt Central Station, which is famous for its drug scene and brothels, as a place to avoid, especially at night. Nevertheless, these young people are aware that the representations on Instagram differ from reality. 'Everyone presents themselves in the best way possible,' Sarah reflects. Finn states: 'no one would post that they are feeling down today, but to show how great their lives are... and this is just so superficial.' Moreover, he feels that Instagram is a social media platform characterized by detachment: 'You never know how someone meant something.' 


\section{Discussion: Adolescents and the 'instagramability' of places}

The practices for producing space on social media are highly intertwined with each other. Home is a place that can be understood as a symbol for ordinary everyday life and does not seem exciting enough to share with a larger crowd. At first glance, the young people in our study do not take part in the digital construction of everyday life that users of social media platforms are deemed responsible for (Boy and Uitermark (2017)). Whilst not tagging their home, they actively decide to tag other places they perceive as exciting, exotic, cool and the opposite of unremarkable. In doing so, they ascribe special meaning to the places they select for geotagging and attach greater importance to them than to their places of everyday life. As Isabella states, she tags remarkable places to maintain a certain self-image. This practice leads also to segmentation of space/place, because non-remarkable places are perceived as unimportant and remain largely invisible, as Boy and Uitermark (2017), Butler et al. (2018), Fekete (2015), Kelley (2013), Lundgren and Johansson (2017) and Shelton et al. (2015) all state. Moreover, as we have seen, some think about the suitability of a location before taking a picture and have decided views of what is 'Instagram worthy' while being aware that their pictures are staged and only show a small segment of reality. Isabella perceives her Instagram feed as a business card or portfolio, where the first impression must be flawless and shine a good light on her - hence her intensive endeavours to curate her profile and photos. She perceives spaces through their 'instagramability', meaning that for her personal experience and production of space are only possible through Instagram. Therefore, social media not only lead to the segmentation and altered meaning of space but also enable the curation of space (Boy and Uitermark (2017)).

The practice of geotagging exceptional places becomes a practice for constructing places as status symbols, meaning places are not only 'upgraded' but define a persons' affiliation to a certain group. Upgraded places can received a lot of attention, as we will argue later. a Within this process in which social media platforms - as coded infrastructure - act as mediators. In addition to constructing places as status symbols, geotags serve as means to archive digital memories and to validate the user's adventures. Thinking of places as status symbols enables us to understand the implications for their offline equivalents. There are countless examples of places that are overrun by young people due to their 'Insta-fame' (Spiegel, 2018). Some places accept or even foster the possibility that they might go viral by identifying 'good' Instagram-worthy locations. Kampen, a municipality on the German isle Sylt, for example, introduced selfie points (see Figure 2) throughout the town (Kampen, n.d.). Fostering such selfie points not only alters the meanings of these places and, therefore, influences perception of them, but also inevitably leads to further segmentation of space by encouraging the selection of certain specific locations. 


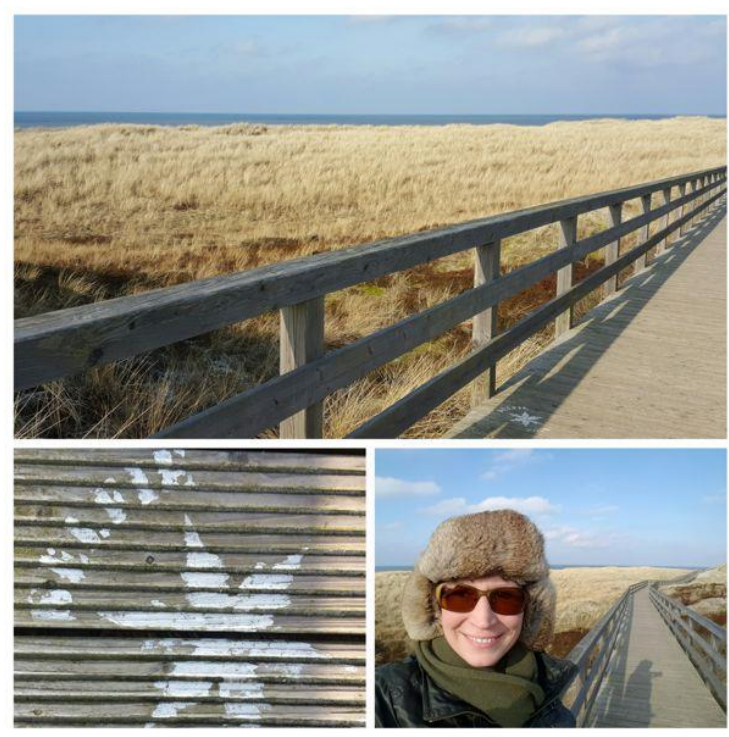

Figure 2: Official selfie point in Kampen, Sylt (Source: https://www.meyrose.de/wp-content/uploads/Kampen-Selfie-Point-Ines-Meyrose-Sylt-201602Collage.jpg)

The young people in our study transform the places they share by editing them or applying filters. They place value on the artistic or aesthetic appearance of their Instagram feed, where places are intended to look more 'beautiful' and more 'positive' than they perhaps are in reality; the young people take an active part in their aesthetic transformation (Boy \& Uitermark, 2017). This could lead to the assumption that places that are not presented on social media platforms might be 'ugly', 'negative' or not worth visiting (Butler et al. (2018). Moreover, this leads to questioning whether Instagram results in an ethnic division, as Fekete (2015) concluded in her study of Foursquare, or contributes to the unification of places. With its 'explore' feature, Instagram serves not only as a platform for uploading and sharing pictures but also as a navigation tool. By geotagging their pictures, users facilitate navigation for other users as well as the replication of places. Boy and Uitermark (2017) observe the same phenomenon in their study. As Melanie stated, she uses the 'explore' feature to find new locations (e.g. when going on vacation). Even though she knows that places are being presented with a certain aesthetic and look better on Instagram, she still perceives their representation as 'more honest'. Consequently, Instagram produces a certain truth that is mediated through coded infrastructures and the perception and experience of other users.

As our results show, young people often select a location to photograph and upload to Instagram, and use a particular filter in order to create a certain aesthetic. They are driven by a desire to share and show off places that are exceptional; they use Instagram as a means of self-staging, giving us an explanation as to why they present and perceive places in a certain way. Our analysis confirms that the digital condition facilitates social media like Instagram, where digital spaces are being produced (Stalder 2018). These spatial practices produce a code/space (Kitchin \& Dodge, 2011), which leads to the emergence of new perspectives for understanding and analysing space within social media. The perspectives are somewhat fuzzy 
and difficult to distinguish due to their high degree of intertwinement; social media platforms like Instagram mediate this new form of spatial perception (Leszczynski, 2015). The spatial practices discussed here challenge us to think about new perspectives on digital spaces as well as appropriate methods within geography education. Kanwischer and Schlottmann (2017) emphasize the inseparability of reflective abilities in the context of education for digital maturity. Therefore, geography education needs to adopt a reflective approach that enables young people to reflect on their spatial practices and perception as well as on their relation to the world (Kanwischer \& Schlottmann, 2017).

\section{Conclusions and future work}

To understand how space is produced through social media and which processes of production and reception emerge among young people against the background of the changed spatial allocation of meaning through digitization, we analysed interviews with adolescents on their use and spatial experience on Instagram. We presented a first glimpse into our data, which gives us an impression of how adolescents produce and perceive places on social media. Software not only enables the production of a code/space but also leads to new spatial practices. We identified several practices using open coding that emerge in the production of code/space: choosing, geotagging and editing locations, and navigating through them. At the same time, social media shape adolescents' spatial perception. Our analysis not only demonstrates a change in the conditions under which space is produced, but also leads to questions regarding different aspects of the production of space: How and why do spatial practices differ? What role does the platform design play, and how does it enable these practices? What direct effects do social media have on the perception of spaces? What effects do spatial constructions on social media have on young people's own actions? How do algorithms co-produce space and shape spatial perception? How does the role of the subject in georeferenced social media change?

In the next step, we will transfer into categories our codes regarding young people's spatial practices, perception of space, and awareness of how media shape their identity, spatial perception and actions. We will then form core categories that enable us to articulate a theory concerning the production of space in social media. Since social media play such a major role and shape an individual's self-image and relation to the world, how to empower the critical questioning of self-image and spatial representations in social media also arises. Geography education must take into account these changed conditions and spatial practices, responding with appropriate concepts that integrate social media and consider these questions.

\section{Acknowledgement}

This work was supported by the German Federal Ministry of Education and Research under Grant 01JKD1707. 


\section{References}

Ash, J., Kitchin, R. \& Leszczynski, A. (2018). Digital turn, digital geographies? Progress in Human Geography, 42(1), 25-43.

Boy, J. D. \& Uitermark, J. (2017). Reassembling the city through Instagram. Transactions of the Institute of British Geographers, 42(4), 612-624.

Breuer, F. (2010): Reflexive Grounded Theory. Eine Einführung für die Forschungspraxis. Heidelberg, Germany: VS Verlag.

Bruns, A. \& Burgess, J.E. (2011). The use of Twitter hashtags in the formation of ad hoc publics. Proceedings of the 6th European Consortium for Political Research (ECPR)

General Conference 2011. Reykjavik, Iceland: University of Iceland.

Bruns, A. \& Stieglitz, S. (2014). Twitter data: What do they represent? it - Information Technology, 56(5), 240-245.

Burgess, J.E., Marwick, A. \& Poell, T. (Eds.) (2017). The SAGE Handbook of Social Media. London.

Butler, A., Schafran, A. \& Carpenter, G. (2018). What does it mean when people call a place a shithole? Understanding a discourse of denigration in the United Kingdom and the Republic of Ireland. Transactions of the Institute of British Geographers, 43(3), 496-510.

Fekete, E. (2015). Race and (online) sites of consumption. Geographical Review, 105(4), 472-491.

Frankfurter Rundschau (2019). Greta im Zug. Greta Thunberg: Tweets der Deutschen Bahn rufen Datenschützer auf den Plan. Retrieved from https://www.fr.de/politik/greta-thunberg-deutschebahn-tweets-datenschutz-13335455.html

Frankfurter Rundschau (2020). Eskalation in Nahost. Mehrere US-Soldaten beim iranischen Raketenangriff vergangene Woche im Irak verletzt. Retrieved from https://www.fr.de/politik/donald-trump-hetzt-ueber-twitter-iran-konflikt-gegen-soleimani-zr13391601.html

Highfield, T. \& Leaver, T. (2016). Instagrammatics and digital methods: studying visual social media, from selfies and GIFs to memes and emoji. Communication Research and Practice, 2(1), 47-62.

Kampen (n.d.). Selfie Points. Retrieved from: https://www.kampen.de/selfiepoint.html

Kanwischer, D. \& Schlottmann, A. (2017). Virale Raumkonstruktionen - Soziale Medien und Mündigkeit im Kontext gesellschaftswissenschaftlicher Medienbildung. Zeitschrift für Didaktik der Gesellschaftswissenschaften, 8(2), 60-78.

Kelley, M. J. (2013). The emergent urban imaginaries of geosocial media. GeoJournal, 78(1), 181-203.

Kitchin, R. \& Dodge, M. (2011). Code/Space. Software and Everyday Life. Cambridge, USA: MIT Press.

Leszczynski, A. (2015). Spatial media/tion. Progress in Human Geography, 39(6), 729-751.

Lundgren, A. S. \& Johansson, A. (2017). Digital rurality: Producing the countryside in online struggles for rural survival. Journal of Rural Studies, 51, 73-82.

Medienpädagogischer Forschungsverbund Südwest (mpfs) (2018). JIM-Studie 2018. Jugend, Information, Medien. Basisuntersuchung zum Medienumgang 12- bis 19-Jähriger. Stuttgart, Germany: mpfs.

Rogers, R. (2013). Digital Methods. Cambridge: MIT Press.

Shelton, T., Poorthuis, A. \& Zook, A. (2015). Social media and the city: Rethinking urban socio-spatial inequality using user-generated geographic information. Landscape and Urban Planning, 142, 198-211.

Spiegel (2018). Reisefotos in sozialen Medien - 'Instagram ruiniert diese Orte'. Retrieved from https://www.spiegel.de/reise/fernweh/reisefotos-in-sozialen-medien-instagram-ruiniert-dieseorte-komplett-a-1233701.html

Stalder, F. (2018). The digital condition. Cambridge, UK: Polity. 